Florida International University FIU Digital Commons

4-18-2012

\title{
Personal Control and Responsibility Measure: A Psychometric Evaluation
}

Alan Meca

Florida International University, ameca002@fiu.edu

DOI: $10.25148 /$ etd.FI12072703

Follow this and additional works at: https://digitalcommons.fiu.edu/etd

\section{Recommended Citation}

Meca, Alan, "Personal Control and Responsibility Measure: A Psychometric Evaluation" (2012). FIU Electronic Theses and Dissertations. 665.

https://digitalcommons.fiu.edu/etd/665 


\section{FLORIDA INTERNATIONAL UNIVERSITY}

Miami, Florida

PERSONAL CONTROL AND RESPONSIBILITY MEASURE:

A PSYCHOMETRIC EVALUATION

A thesis submitted in partial fulfillment of the

requirements for the degree of

MASTER OF SCIENCE

in

PSYCHOLOGY

by

Alan Meca

2012 
To: Dean Kenneth G. Furton

College of Arts and Sciences

This thesis, written by Alan Meca, and entitled Personal Control and Responsibility Measure: A Psychometric Evaluation, having been approved in respect to style and intellectual content, is referred to you for judgment.

We have read this thesis and recommend that it be approved.

Dionne P. Stephens

Mary J. Levitt

William M. Kurtines, Major Professor

Date of Defense: April 18, 2012

The thesis of Alan Meca is approved.

\begin{tabular}{r} 
Dean Kenneth G. Furton \\
College of Arts and Sciences \\
\hline Dean Lakshmi N. Reddi \\
University Graduate School
\end{tabular}

Florida International University, 2012 


\section{DEDICATION}

The greatest irony of all is that we as humans are granted an innate curiosity to try to answer the endless questions in the universe but have only a fraction of time to do so. This paper is dedicated to my father, Gaston Meca (1947-2009), he forsook his hopes and dreams so that I could live mine. His last wishes will never be forgotten and I will forever remember to enjoy progress and move forward despite the irony of the human condition. 


\section{ACKNOWLEDGMENTS}

This paper, that seeks to further the scientific literature on positive youth development, could not have been possible without Dr. Kurtines who has given me the privilege of working at the Miami Youth Development Project and guided me as a mentor through my project. I would further like to express my sincere regards to the rest of the graduate students at the YDP Lab and all that have ever worked towards the collection of my data set. To my friends, I thank them for helping balance my work with leisure. And finally, to my family, I thank you for the determination that has been imparted in me, to the expectations that have guided me, and to the understanding and aid you have provided me that has allowed me to remain a full time student. 


\author{
ABSTRACT OF THE THESIS \\ PERSONAL CONTROL AND RESPONSIBILITY MEASURE: \\ A PSYCHOMETRIC EVALUATION \\ by \\ Alan Meca \\ Florida International University, 2012 \\ Miami, Florida \\ Professor William M. Kurtines, Major Professor
}

The Changing Lives Program (CLP) is a Positive Youth Development (PYD) program that seeks to empower adolescents attending voluntary alternative high schools to take control and responsibility over their lives so they may change their negative life pathways into positive ones. The current study seeks to evaluate the CLP's Personal Control and Responsibility Measure, an eight item scale devised to assess individuals control and responsibility over life change goals (CRLCG) and life in general (CRG). Using a weighted least squares mean and variance adjusted (WLSMV) estimator available in Mplus for categorical variable modeling, the current study ran confirmatory factory analysis on two theoretically possible models, a single factor and a two factor structure. After items regarding control over consequences dropped, results confirmed the hypothesized two factor model (CRLCG and CRG). Furthermore, analysis of measurement invariance found the factor structure form, factor loadings, and intercepts to be invariant across condition, gender, ethnicity, and time (time 1 and 2). Limitations of the current study and implications for future evaluations of the Changing Lives Program (CLP) are discussed. 


\section{TABLE OF CONTENTS}

CHAPTER

PAGE

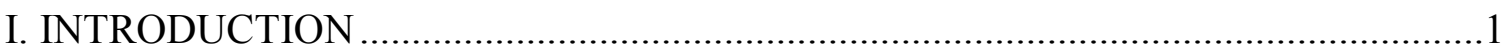

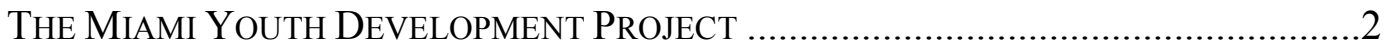

The Changing Lives Program (CLP) ..........................................................

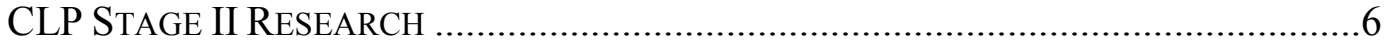

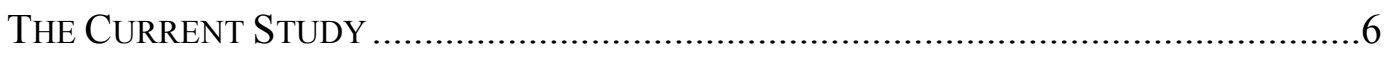

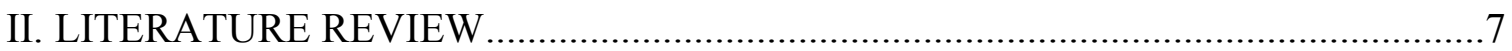

Promoting Positive Youth DEVELOPMENT ....................................................

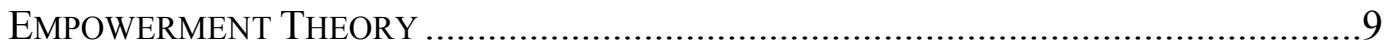

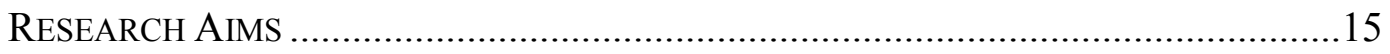

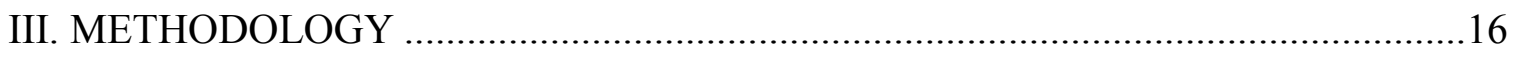

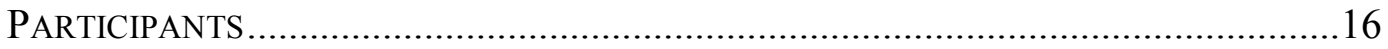

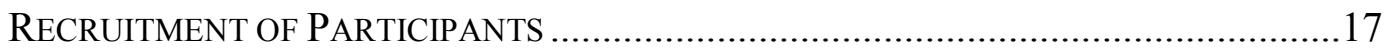

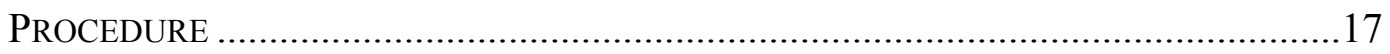

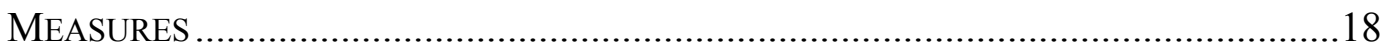

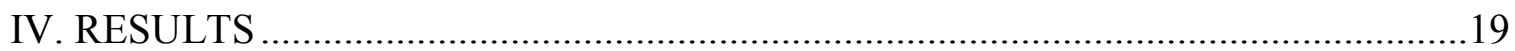

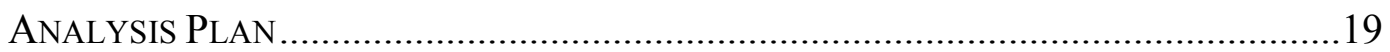

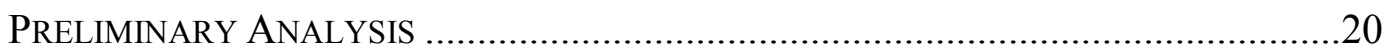

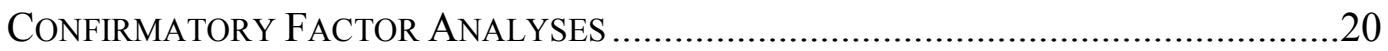

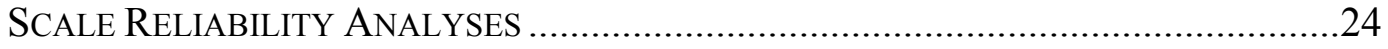

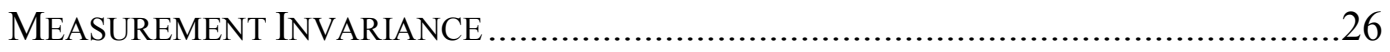

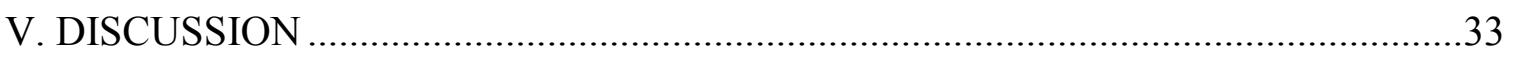

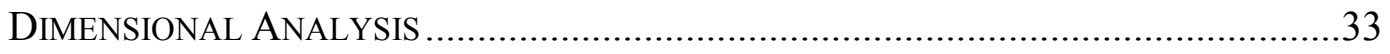

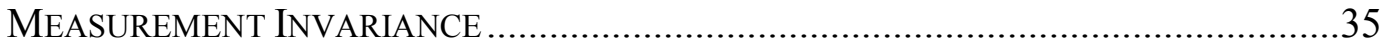

LIMITATIONS AND DIRECTIONS FOR FUTURE RESEARCH …....................................36

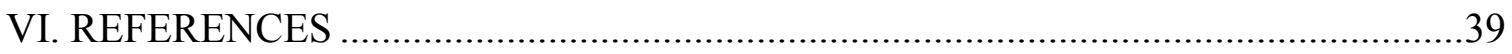




\section{LIST OF TABLES}

TABLE

PAGE

1. Personal Control and Responsibility Measure ................................................. 14

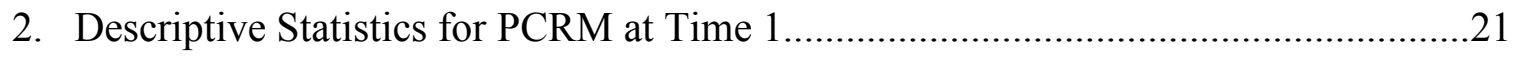

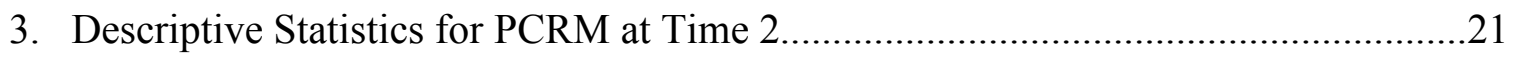

4. Model Fit for Confirmatory Factor Analysis .........................................................23

5. Measurement Invariance by Condition .................................................................28

6. Measurement Invariance by Gender ..................................................................29

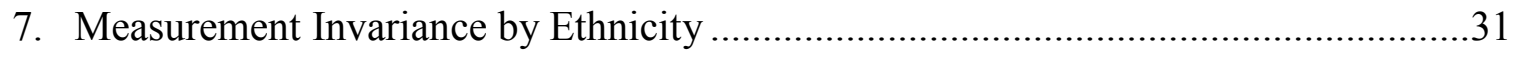

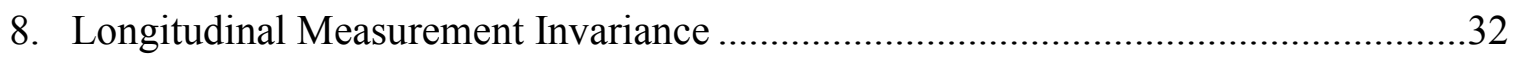




\section{INTRODUCTION}

As described by Schwartz, Côté, and Arnett (2005), Erikson's (e.g., 1950; 1968; 1987) writings suggest that in a postindustrial society, a sense of agency (conceptualized as a sense of self-direction and free exercise of choice) would enhance individuals' capabilities towards forming a coherent sense of identity. Consistent with a participatory transformative approach (Kurtines, Azmitia, \& Alvarez 1992; Kurtines, Berman, Ittel, \& Williamson, 1995; Kurtines et al., 2008a), the process of forming a sense of self identity is marked by an active, self-directed exploration of available identity alternatives, and commitment to a sense of self willing to take control and capable of being responsible for life choices and the consequences of their choices (Waterman, 1992). Under the participatory transformative approach, the individual both shapes and is shaped by the coconstruction of reality. Self and society are two sides of the same coin (Meadn, 1967). Identity development thus occurs at the interface between society and the self (Kurtines, Azmitia, \& Alvarez 1992; Kurtines, Berman, Ittel, \& Williamson, 1995). On one hand, social institutions (e.g. family, schools, and government, etc.) are expected to develop cognitive and psychosocial competencies (i.e., social skills, educational credentials, etc.) in individuals and on the other hand, individuals demonstrate integrity of character by assuming control over their choices and their consequences (Waterman, 1992). Thus, the interaction between society and self is one in which both mutually influence each other (Briones, 1997).

In this context, empowerment theory seeks to promote a sense of competency, while fostering the knowledge and encouraging the behaviors needed for enacting the 
evolution of the society. In merging the two theories, empowerment becomes the process by which society develops functioning citizens that take control and responsibility over their decisions and society undergo transformation and evolution. This successful operation of the process of empowerment is often minimal or absent in the case of disadvantaged and marginalized youth it is therefore especially important for ensuring their eventual participation in transformative social change (Kurtines et al., 2008a). For example, although research has found that adolescence is not universally a period of stress and storm (Arnett, 1999), the transition from adolescences to adulthood often poses a formidable challenge for disadvantaged adolescents (Berman, Kurtines, Silverman, \& Serafini, 1996; Wilson, Rodriguez, \& Taylor, 1997). Consequently, it becomes important to develop interventions to empower troubled youth and promote competencies, particularly those that help young people redefine their sense of self and identity as agents capable of self and societal change.

\section{The Miami Youth Development Project}

The Miami Youth Development Project (YDP) is a community-supported positive youth development program that developed as a response to the growing community need for resources that troubled youth can use to reconnect with their lives and families. The program draws on community-university collaboration and principles consistent with the outreach research model (Kurtines et al., 2008a) to foster positive youth development among the culturally diverse and multi-problem adolescents attending Miami's alternative high schools. As described below, the YDP draws on a developmental intervention fusion of treatment, prevention, and developmental science to create 
effective, feasible, affordable, and sustainable intervention programs that meet the community needs in real-world settings (Kurtines et al., 2008c).

\section{The Changing Lives Program (CLP)}

The Changing Lives Program (CLP) was created using a developmental intervention approach (Kurtines et al., 2008b) and is currently being implemented by the Miami YDP as a selective/indicated PYD program targeting multi-problem youth in alternative high schools in the Miami Dade County Public Schools. Students in alternative schools are typically on a negative life-course pathway and at risk for multiple negative developmental outcomes and/or are engaged in multiple problem behaviors. The CLP provides on-site counseling services in all of the M-DCPS voluntary alternative high schools. As described in Montgomery and colleagues (2008), the primary intervention goal of the CLP is to create contexts that empower troubled adolescents to transform basic features of their sense of self and identity (e.g., life goals, direction and purpose, etc.) and take control and responsibility over their lives in ways that also result in positive change in problem domains, thereby changing their "negative" life pathways into positive ones.

For its developmental theoretical framework, the CLP draws on an integration of Erikson's (1968) psychosocial developmental theory and Elder's (1998) life course theory. The psychosocial developmental life course approach (Kurtines et al., 2008c) considers identity a relatively stable "self-structure" (i.e., the self-constructed, coherent, and dynamic organization of drives, abilities, beliefs, and personal history) that, from a sociological perspective (Elder, 1998), serves as an individual's "steering mechanism" 
for directing choices and actions within the "constraints and opportunities of history and social circumstances throughout the duration of a life course" (Elder, 1998, p. 961).

The YDP's psychosocial developmental life course approach adopts a view of adolescence as the developmental period during which the individual is first confronted with the challenge and responsibility of choosing the goals, roles, and beliefs about the world that give life direction and purpose, as well as coherence and integration, and, as such, adolescence is a transitional period of increased likelihood of a radical break or departure from a previous life-course pathway (Montgomery et al., 2008). From the perspective of life-course theory (Elder, 1998), transitions in the life-course pathway are marked by qualitative state changes that are elements of the greater life trajectory. A qualitative state change may represent a "turning point" or a change in either the direction of the current life trajectory (e.g., from negative to positive) or in the life trajectory itself (e.g., focus on academic success) that may either be short term or long term relative to the individual's life history.

A Participatory Transformative Intervention Approach. In the context of its short term intervention work for promoting positive life course change with adolescents, the CLP draws on a participatory transformative theoretical framework (Montgomery et al., 2008). The participatory transformative framework extends and refines the psychosocial developmental concepts of self and identity as articulated by psychosocial developmental theory (Erikson, 1968) and sociological life course theory (Elder, 1998) by linking them to the concept of mastery experiences (Bandura, 1997). The CLP uses youth-directed transformative activities as its key behavioral intervention strategy for 
facilitating adolescent empowerment to form a positive sense of self and identity (see Kurtines, et al., 2008).

Successful engagement in self-selected and self-directed activities has been hypothesized to empower youth by strengthening intrinsic motivation to achieve life goals and develop a sense of control and responsibility with respect to life activities (Bandura, 1997; Seligman \& Csikszentmihalyi, 2000). By intentionally identifying problems and engaging in transformative activities to solve these problems (changing the way things are for the better), adolescents become the empowered "experts" in their own lives and learn "to see a closer correspondence between their goals and a sense of how to achieve them, gain greater access to and control over resources and gain mastery over their lives" (Zimmerman, 1995, p. 583).

Although the CLP's key “intervention strategy" is comprised primarily of facilitating participants' engagement in transformational change producing "activities", it is the quality of the cognitive and affective components of mastery experiences generated by transformative activities that are hypothesized to have the potential to transform the meaning and significance of all types of life course experiences (Montgomery et al., 2008). From a psychosocial developmental life course perspective (Arnett, Kurtines \& Montgomery, 2008), mastery experiences that result in change in a participant's experiences of "self" and "identity" are among the most empowering types of transformational change because such change promotes the positive development of the steering mechanism that directs the course of their lives over the long haul. Thus, the 
CLP intervention seeks to promote proactive transformative activities that facilitate the type of mastery experience that stimulates the development of a positive sense of identity.

\section{CLP Stage II Research}

Consistent with Rounsaville et al.'s (2001) recommendations for the development and evaluation of interventions, the on-going evaluation of intervention outcomes within the CLP has taken place as part of the Stage II of the CLP MLC program evaluation (Montgomery et al., 2008). Stage II evaluation consists of the extension and refinement of previous Stage I pilot/feasibility testing, manual/protocol writing, infrastructure development, and measure development. The CLP Stage II evaluation focuses primarily on psychometric evaluation of measures and short-term controlled outcome studies in the preliminary evaluation of the CLP intervention.

\section{The Current Study}

Previous Stage II evaluation of the CLP has suggested that participation in the CLP intervention is associated with increases in positive identity development and decreases in problem behaviors (Eichas et al., 2010). An important objective for future CLP Stage II evaluation is a closer examination of the intervention processes hypothesized to underlie CLP intervention outcome. As noted, the CLP intervention seeks to facilitate mastery experiences among its participants by specifically targeting engagement in transformational change producing activities. Engagement in these transformative activities is hypothesized to promote youth's sense of control and responsibility over their lives. A critical next step towards examining CLP intervention 
processes and links between these processes and positive identity development is to identify valid and reliable measures of the key constructs that constitute the CLP's intervention framework. Toward that end, the goal of the current study was to evaluate the measurement properties of the Personal Control and Responsibility Measure (PCRM), a measure used in YDP research to capture youth's sense of control and responsibility for their lives. Consistent with Lerner's (2005) recommendations for positive youth development research, this study evaluated the PCRM's factor structure and its measurement equivalence across differential groups (sex and race) and temporal levels of the system (Pre and Post evaluation).

\section{LITERATURE REVIEW}

\section{Promoting Positive Youth Development}

The Positive Youth Development (PYD) perspective represents a shift away from the tendency to view adolescence as a period of stress and storm and youth as both dangerous and endangered or as problems to be managed (Lerner, 2005). Emerging out of a developmental systems perspective, the literature on promoting positive development has emphasized the possibility of adaptive developmental relations between individuals and their contexts and the potential plasticity of ontogenetic change as a fundamental strength of all humans across the entire life span (Lerner, 2005). Positive youth development programs seek to do more than treat or prevent problem behaviors or undesirable symptoms (Benson, Scales, Hamilton, \& Sesma, 2006; Csikszentmihalyi, 1998; Damon, 2004; Kurtines et al., 2008; Lerner, Fisher, \& Weinberg, 2000). Furthermore, PYD programs seek to maximize individuals' potential and positive 
developmental outcomes, "not only as an essential end in itself but also as a means of preempting any self-destructive or antisocial tendencies that can arise when there is a vacuum of positive activity" (Damon, 2004). As emphasized by Damon, if individuals' strengths are aligned with resources for healthy growth across contexts (the home, the school, and the community) then enhancements in positive functioning and development may occur.

\section{Empowerment in positive youth development. Positive Youth Development} Programs seek to engage youth in productive activities and to empower them to take control of their lives instead of targeting symptom reduction or correcting, curing, or treating maladaptive behaviors (Catalano et al., 2004). By creating contexts and providing "developmental assets" (the social and ecological "nutrients" for the growth of healthy youth), individuals are able to develop in positive ways (Benson, et al., 2006; Lerner, 2005). Among these developmental assets, Benson (1997) included empowerment (responsibility, service, and expectations) as one of eight critical categories of positive development. Benson (1997) asserted that both young people being given useful roles in the community (youth as resource) and serving one hour or more per week (service to other) are essential assets for facilitating empowerment.

The empowering process, as proposed by Zimmerman $(1995,2000)$ is one in which opportunities are provided to increase capabilities and confidence, learn and practice skills, exert control, and influence decisions are fundamental. Consistently, the PYD literature has found that participation in activities that provide these opportunities for youth (e.g., after school programs) play a role in healthy adolescent development and 
resilience (Catalano et al., 1996; Furstenberg \& Hughes, 1995; Ramirez-Valles, Zimmerman, \& Juarez, 2000; Zimmerman \& Maton, 1992). As suggested by Marsh (1992) and highlighted by Zimmerman and colleagues (2011), participation in out-ofschool programs leads to the development of a positive self-concept and an increased sense of control, allowing youths to develop social and cognitive skills, competency, socio-environmental mastery and establish connections with positive adult role models, pro-social peers, and community institutions. Thus, empowerment stands as a key process underlying positive youth development programs.

\section{Empowerment Theory}

A multi-level construct of analysis. Empowerment is a multi-level open construct of the process by which people (psychological empowerment), organizations (organizational empowerment), and communities (community empowerment) gain mastery over the issues that concern them (Zimmerman, 1990; 1995). As conceptualized by Zimmerman (1990), empowerment is not an absolute threshold that allows the individual, organization, or community to be labeled as empowered upon reaching it. Instead, empowerment at all levels of analysis can vary in intensities that may change over time. Furthermore, empowerment across all levels analysis focuses on the interactions between individuals and environments that are culturally and contextually defined (Zimmerman, 1990). The CLP specifically aims to intervene at the level of psychological empowerment to promote empowerment at the individual level.

Psychological empowerment. Psychological empowerment refers to an individual's ability to make personal life decisions (Schulz, Israel, Zimmerman, \& 
Checkoway, 1995), employ a proactive approach to life, perception of personal control, and a critical understanding of the sociopolitical environment (Zimmerman, 1990; 1995). Psychological empowerment is not simply an individually-oriented conception that neglects contextual factors and solely focuses on intrapsychic variables such as motivation to control, locus of control, and self-efficacy (Zimmerman, 1990). Instead, psychological empowerment is the understanding of "how what goes on inside one's head interacts with what goes on in one's environment to enhance or inhibit one's mastery and control over the factors that affect one's life"(Zimmerman, 1990 p. 174) and thus requires a contextual analysis to be fully understood (Zimmerman, 1990; 1995). While an individual may not have any real power in a political sense, within a contextual framework, it is still possible to be considered empowered so long as the individual has an understanding of what choices can be made given different situations (Zimmerman, 1990). Being empowered is the knowledge that individuals can choose whether to fight or retreat, to be dependent or independent, and to organize or wait (Zimmerman, 1990).

Measuring empowerment outcomes. Empowering processes are a series of experiences that provide individuals, organizations, and communities with the opportunity to examine the relationship between their goals and a sense of how to achieve them (Cornell Empowerment Group, 1989; Mechanic, 1991; Zimmerman, 1990). Empowering processes include the opportunity to develop skills, to learn about resource development and management and to work with others towards a common goal (Zimmerman, 1995). While empowering processes are the means by which people, organizations, and communities become empowered, empowerment outcomes are the consequences of those processes and defined by the "specific measurement operations 
that may be used to study the effects of interventions designed to empower participants" (Zimmerman, 1995). Empowerment outcomes vary across levels of analysis; however, empowerment research has consistently identified associations at the individual level between empowering processes and empowerment outcomes, such as perceived control variables, skill development, and measures of participation and community involvement (Balcazar, Seekins, Fawcett, \& Hopkins, 1990; Chavis \& Wandersman, 1990; Stone \& Levine, 1985; Zimmerman \& Rappaport, 1988; Zimmerman, Israel, Schulz, \& Checkoway, 1992).

Components of psychological empowerment outcomes. While psychological empowerment varies across context and population (Rappaport, 1984; Zimmerman, 1995), three concepts have been found to be consistent across levels of analysis as empowerment outcomes: 1) intrapersonal (i.e., domain specific perceived control, domain specific self-efficacy, motivation control, and perceived competency), 2) interactional (i.e., critical awareness, understanding causal agents, self-development, skill transfer across life domains, and resource mobilization), and 4) behavioral (i.e., community involvement, organizational participation, and coping behaviors).

The intrapersonal component. The Intrapersonal component (Zimmerman, 1995) refers to the individuals' concept and self-perception of their capacity to influence social and political systems that are important to them. This component is inclusive of domainspecific perceived control (Paulhus, 1983), self-efficacy, motivation to exert control, and perceived competence. 
The interactional component. The interactional component encompasses the transaction between the individual(s) and environments that engage in successful mastery over social or political systems (Zimmerman, 1995). Included within this category is knowledge over resources needed to achieve goals, understanding causal agents (Sue \& Zane, 1980), a critical awareness of one's environment (Freire, 1973; Kieffer, 1984), and the development of decision-making and problem-solving skills necessary to actively engage one's environment.

The behavioral component. The behavioral component of PE refers to the actions that individuals take to exercise their influence on their environment, specifically stated by Zimmerman (1995) to be through participation in community organizations and activities. Included in the behavioral component is participation in community and service organizations.

Setting specific examples of psychological empowerment. Psychological empowerment (a) varies across people in its manifestation of different perceptions, skills, and behaviors across people (Rappaport, 1984) (b) requires different beliefs, competencies, and actions in order to master different settings, and (c) changes across time (Zimmerman, 1995). Zimmerman (1995) provided examples of psychological empowerment across levels of analysis as well as the contextually appropriate empowerment outcomes. For example, in a mutual help group much like the intervention groups in the CLP, Zimmerman (1995) stated that members, who are dealing with specific issues, would not be concerned with sociopolitical control but rather personal control (intrapersonal component). He further stated that potential outcome variables, 
consistent with the population and setting, would be problem-solving and coping skills (interactional component), as well as taking on leadership roles, reaching out to other members of the group, and getting involved in the community (behavioral).

Psychological empowerment within the Changing Lives Program. Consistent with the empowerment theory described above, the Miami Youth Development Project seeks to foster personal control, perceived competency, problem solving skills, and engagement of leadership roles within the CLP intervention by engaging in transformative activities in order to change participants' negative life trajectories into positives ones. As described by Montgomery and colleagues (2008), troubled youth, by intentionally identifying problems and engaging in transformative activities to solve these problems (changing the way things are for the better), become the empowered "experts" in their own lives and learn "to see a closer correspondence between their goals and a sense of how to achieve them, gain greater access to and control over resources and gain mastery over their lives" (Zimmerman, 1995, p. 583).

From a psychosocial developmental life course perspective (Arnett, Kurtines \& Montgomery, 2008), mastery experiences that result in change in a participant's experiences of "self" and "identity" are among the most empowering types of transformational change because such change promotes the positive development of the "steering mechanism" that directs the course of their lives "over the long haul." Thus, the CLP intervention seeks to promote proactive transformative activities that generate the type of mastery experiences that promote increased control and responsibility over life change goals and in turn the development of a positive sense of self and identity. 
Personal Control and Responsibility Measure. The Personal Control and Responsibility Measure (PCRM; Rice, Berman, Ferrer, \& Kurtines, 1996) was created in order to assess individual's development of mastery over their own lives. The PCRM (see Table 1) is an eight-item measure that asks participants to rate how much perceived control and responsibility they have over their decisions and actions, as well as outcomes and consequences of their self-selected life change goals (CRLCG) and over their life in general (CRG). Previous evaluations of the CLP using the PCRM have used composite scores of control and responsibility over CLRCG and CRG (Meca et al., 2010).

Table 1: Personal Responsibility Measure

For your life change goal

1a. How much control do you have over your decisions and actions (What you think, feel, and do)?

2a. How much responsibility do you have for your decisions and actions (What you think, feel, and do)?

3a. How much control do you have over the outcomes/consequences of your actions (what happens)?

4b. How much responsibility do you have for the outcomes/consequences of your actions (what happens)?

For your life in general

1b. How much control do you have over your decisions and actions (What you think, feel, and do)?

2b. How much responsibility do you have for your decisions and actions (What you think, feel, and do)?

3b. How much control do you have over the outcomes/consequences of your actions (what happens)? 
4b. How much responsibility do you have for the outcomes/consequences of your actions (what happens)?

$1=$ None, $2=$ A Little, $3=$ Some, $4=$ A Lot, $5=$ Total

However, the factor structure of the PCRM has never been confirmed, and while a two factor solution (CRLCG and CRG) is one possible model, it is not the only theoretically meaningful factor solution. For example, a conceptual distinction may exist between central control (control over an individual's actions; Table 1, items 1a and 1b) and consequential control (control over the consequences of an event or an individual's actions; Table 1, items $3 \mathrm{a}$ and $3 \mathrm{~b}$ ) that previous CLP research has not taken into account (Thompson, Nanni, \& Levine, 1994). In line with this idea, previous studies examining cancer patients' control over the consequences of cancer was significantly more strongly associated with low levels of depression and anxiety than was the perception of control over the cancer itself. Thus, the current study sought to examine the factor structure with and without the items $3 a$ and $3 b$ in the hopes of conceptualizing primary control over life change goals and life in general.

\section{Research Aims}

Before future studies can seek to examine the hypothesized relationship between participation in the CLP intervention and control and responsibility over life change goals, psychometric evaluations of the Personal Control and Responsibility Measure must be conducted in order to assess for its validity and reliability. Thus, as part of the evaluation of the Changing Lives Program, the current sought to evaluate 
1) Two theoretically plausible factor measurement model for the Personal Control and Responsibility Measure, specifically,

a. A one factor structure of sense of control and responsibility (CR)

b. A two factor structure of control and responsibility over life change goals (CRLCG) and life in general (CRG),

2) the scale reliability of the extracted factors,

3) measurement invariance across condition, gender, and ethnicity,

4) and finally longitudinal measurement invariance across baseline and postintervention assessment

\section{Methodology}

\section{Participants}

The data were obtained from the Miami Youth Development Project (YDP) at Florida International University. Data were collected via questionnaires prior to intervention and after intervention. Only participants whose measurement profile matched the measurement profile for the current project were drawn. The analysis was conducted on a sample of 405 adolescents in the intervention (114) and control group (291) who have completed pretest assessments. The age of the participants ranged from 13 to 19 years of age (Mean=15.93, $\mathrm{SD}=1.12)$. The sample was composed of African American (178) and Hispanics (120), White Non-Hispanic (21), Other (17), Bi-Ethnic (16), Native American/Alaskan Native (3), and Asian/Pacific Islander (1). Across gender, the sample consisted of 180 females and 161 males. 


\section{Recruitment of Participants}

Because the evaluation was implemented in a "usual care"' practice in community settings, participants were recruited to the CLP using the Miami Dade County Public School counseling criteria for alternative high schools (through self-referral or through referral from the school counselor/teachers). All participants completed parent consent and student assent forms approved by university and Miami Dade County Public School's Internal Review Board before being assigned to their condition. As part of each school's counseling program, the CLP counseling groups were organized and implemented through the school administration. All of the students who participated in the comparison control condition were randomly selected from a pool of students not self-referred or referred by school counselors or administrators. The participants in the comparison control condition were further selected for not having participated in any of the counseling and guidance programs prior to or during their participation in the heir involvement with the YDP.

\section{Procedure}

Intervention procedure. Participants in the intervention group were assessed at the beginning and end of each semester during their first semester in the program and were then assessed at the end of the following semester for follow-up. Following their baseline assessment, participants began the intervention. Every intervention group was structured and implemented by an intervention team that consisting of one group facilitator, one co-facilitator, and one or two group assistants. All group facilitators and co-facilitators were graduate level students enrolled in either a doctoral or a master's 
level psychology program. Group assistants were undergraduate psychology students who had been trained in the administration of the measures and in participant tracking procedures. The group facilitators and co-facilitators served in a counseling capacity that utilized the CLP's participatory transformative approach (Montgomery, et al., 2008). The intervention groups met for approximately 45 minutes to 1 hour every week for approximately 8 to 12 weeks in either the fall or spring semester.

Control Comparison Condition. Students in the control condition were assessed by research trainees at the beginning and end of each semester. These students did not receive any intervention or psychoeducation during their appointment to the control condition.

Assessment procedures. Participant's assessments were carried out by undergraduate psychology students serving as research trainees at school grounds and during school hours the week preceding the commencement of the semester session and the week after their end. Their training took place at the beginning of each semester and included instruction concerning confidentiality issues, assessment administration, dress code, high school regulations, interviewing strategies, and role-playing of interviews. Assessments took place during the second week of each fall and spring semesters and the last week of each spring semester.

\section{Measures}

Demographics. The Background Information Form (BIF) is a record of demographic information completed by all participants in the YDP program. It provided 
the data used in analyses gender and ethnicity (Hispanic/Latino, African American, NonHispanic White, Bi-ethnic, and Other) as exogenous moderators.

Empowerment outcome: Control and responsibility. The Personal

Responsibility Measure (PCRM; Rice, Berman, Ferrer, \& Kurtines, 1996) was used to measure level of control and responsibility in this study as a marker for mastery experiences as described early. The PCRM is an eight-item measure (see Table 1) that asks participants to rate how much perceived control and responsibility they have over a life challenge on a 5-point Likert-type scale ranging from 1 (no control or no responsibility) to 5 (total control or total responsibility). The PCRM was adapted for the use in the CLP in order to assess the level of control and responsibility participants have over their decisions and actions as well as outcomes and consequences of their life change goals (CRLCG) and over their life in general (CRG). Previous studies reported a Cronbach's alpha of .82 .

\section{Results}

\section{Analysis Plan}

Analysis of the data proceeded in four steps. First, the hypothesized two factor model (control over life change goals, CRLCG; control over life in general, CRG) was evaluated using confirmatory factor analysis. Second, the reliability of the latent variables was assessed using Raykov's (2004) method for estimating scale reliability. Raykov's (2004) method for estimating scale reliability provides a confirmatory factor analysisbased estimate of scale reliability and overcomes the limitations of Cronbach's coefficient alpha. Specifically, Cronbach's alpha will underestimate scale reliability when 
indicators' factor loadings are not equal and can either underestimate or overestimate scale reliability when indicators have correlated measurement errors (Brown, 2006). Third, the championed model was evaluated separately for measurement invariance across condition, gender, and ethnicity using a multiple-group analysis. Fourth, per recommendations of Brown (2006), longitudinal measurement invariance was evaluated using a single-group analysis with latent variables for baseline and follow-up allowed to correlate across time.

\section{Preliminary Analysis}

Tables 2 and 3 provide item correlations for the PCRM and descriptive statistics including values of mean, skewness and kurtosis for Baseline (BL) and four month posttest respectively. Prior to the study's main analysis, data was evaluated for outliers and normality. Outliers were evaluated by examining leverage statistics for each individual; an outlier was defined as an individual with a leverage score four times greater than the mean leverage. No outliers were found. In regards to univariate normality, kurtosis and skewness were within acceptable ranges.

\section{Confirmatory Factor Analyses}

Confirmatory factor analysis was conducted in order to test a one-factor model and a two-factor model specified based on prior work with the PCRM (Rice, Berman, Ferrer, \& Kurtines, 1996). Specifically, it was hypothesized that the eight PCRM items would load onto a life in general factor and a life change factor. Because the items were ordered categorical variables with five levels, a weighted least squares mean and 
Table 2: Descriptive Statistics for PCRM at Time 1

\begin{tabular}{|c|c|c|c|c|c|c|c|c|}
\hline & CRG1 & CRG2 & CRG3 & CRG4 & CRLCG1 & CRLCG2 & CRLCG3 & CRLCG4 \\
\hline CRG1 & 1 & $.621^{* *}$ & $.254^{* *}$ & $.377^{* *}$ & $.427^{* *}$ & $.267^{* *}$ & $.161^{* *}$ & $.239^{* *}$ \\
\hline CRG2 & & 1 & $.261^{* *}$ & $.462^{* *}$ & $.380^{* *}$ & $.404^{* *}$ & $.126^{*}$ & $.288^{* *}$ \\
\hline CRG3 & & & 1 & $.435^{* *}$ & $.224^{* *}$ & $.176^{* *}$ & $.537^{* *}$ & $.325^{* *}$ \\
\hline CRG4 & & & & 1 & $.274^{* *}$ & $.269^{* *}$ & $.385^{* *}$ & $.507^{* *}$ \\
\hline CRLCG1 & & & & & 1 & $.443^{* *}$ & $.407^{* *}$ & $.391^{* *}$ \\
\hline CRLCG2 & & & & & & 1 & $.238^{* *}$ & $.410^{* *}$ \\
\hline CRLCG3 & & & & & & & 1 & $.465^{* *}$ \\
\hline CRLCG4 & & & & & & & & 1 \\
\hline Mean & 4.069 & 4.143 & 3.507 & 3.960 & 3.947 & 4.063 & 3.309 & 3.927 \\
\hline $\mathrm{SD}$ & .923 & .901 & 1.167 & 1.017 & 1.006 & .924 & 1.208 & 1.039 \\
\hline Skewness & -.644 & -.808 & -.316 & -.678 & -.822 & -.978 & -.201 & -.746 \\
\hline Kurtosis & -.369 & .002 & -.696 & -.334 & .258 & .858 & -.863 & -.170 \\
\hline
\end{tabular}

Table 3: Descriptive Statistics for PCRM at Time 2

\begin{tabular}{|c|c|c|c|c|c|c|c|c|}
\hline & CRG1 & CRG2 & CRG3 & CRG4 & CRLCG1 & CRLCG2 & CRLCG3 & CRLCG4 \\
\hline CRG1 & 1 & $.499^{* *}$ & $.155^{* *}$ & $.287^{* *}$ & $.477^{* *}$ & $.348^{* *}$ & $.220^{* * *}$ & $.248^{* *}$ \\
\hline CRG2 & & 1 & $.267^{* *}$ & $.474^{* *}$ & $.341^{* *}$ & $.510^{* *}$ & $.295^{* *}$ & $.396^{* *}$ \\
\hline CRG3 & & & 1 & $.560^{* *}$ & $.146^{*}$ & $.223^{* *}$ & $.637^{* *}$ & $.316^{* *}$ \\
\hline CRG4 & & & & 1 & $.330^{* *}$ & $.425^{* *}$ & $.444^{* *}$ & $.582^{* *}$ \\
\hline CRLCG1 & & & & & 1 & $.417^{* *}$ & $.401^{* *}$ & $.290^{* *}$ \\
\hline CRLCG2 & & & & & & 1 & $.262^{* *}$ & $.482^{* *}$ \\
\hline CRLCG3 & & & & & & & 1 & $.372^{* *}$ \\
\hline CRLCG4 & & & & & & & & 1 \\
\hline Mean & 4.194 & 4.253 & 3.584 & 4.026 & 4.116 & 4.173 & 3.553 & 3.931 \\
\hline SD & .803 & .854 & 1.204 & .989 & .885 & .882 & 1.184 & 1.026 \\
\hline Skewness & -.678 & -1.284 & -.549 & -.949 & -1.020 & -1.047 & -.465 & -.845 \\
\hline Kurtosis & & & & & & & & \\
\hline
\end{tabular}


variance adjusted (WLSMV) estimator available in Mplus for categorical variable modeling (Muthén \& Muthén, 1998-2010) was used. As outlined by Bollen and Long (1993), indices of absolute fit, relative fit, and indices of fit with a penalty function for lack of parsimony were used in order to examine goodness of model fit. These include the chi square test of model fit (which should be statistically non-significant, $p>.05$ ), the Root Mean Square Error of Approximation (RMSEA; which should be less than 0.08), the $\mathrm{p}$ value for the test of close fit (which should be statistically non-significant, $p>.05$ ), the Comparative Fit Index (CFI; which should be greater than 0.95); and the weighted root mean square residual (WRMR; which should be less than .90). As an indicator of absolute fit, the chi-square examines the fit between the hypothesized model and model fit (Byrne, 2001). The CFI serves as an indicator of relative fit and compares the hypothesized model with the independence model. The RMSEA accounts for the error of approximation in the population. Finally, WRMR measures the weighted average differences between the sample and estimated population variances and covariances ( $\mathrm{Yu}$ \& Muthen, 2002; Finney \& Distefano, 2006).

Goodness-of-fit-estimates (see Table 4) for the one-factor model were not consistent with good model fit $\left(\chi^{2}(11)=214.582, p<.001 ; \mathrm{CFI}=.861 ; \mathrm{TLI}=.861\right.$; RMSEA $=.225$, WRMR $=1.724)$. Next, the two-factor model was tested with latent factors (CRLCG and CRG) allowed to covary. Goodness-of-fit-estimates were not consistent with good model fit $\left(\chi^{2}(13)=275.726, p<.001 ; \mathrm{CFI}=.821 ; \mathrm{TLI}=.848\right.$; RMSEA $=.235$, WRMR $=1.929)$. Given similar wording and suggested modification indices, error terms for parallel items (e.g., Table 1, items 1a and 1b) were allowed to covary in order to account for method effects of similar worded items. Goodness-of-fit- 
estimates improved but were still not consistent with good model fit $\chi^{2}(15)=114.023, p$ $<.001 ; \mathrm{CFI}=.929 ; \mathrm{TLI}=.922 ; \mathrm{RMSEA}=.169, \mathrm{WRMR}=1.250)$.

Table 4: Model Fit for Confirmatory Factor Analysis

\begin{tabular}{llllll}
\hline Model & $\chi^{2}(\mathrm{df})$ & CFI & TLI & RMSEA & WRMR \\
\hline Eight Item PCRM & & & & & \\
$\quad$ One Factor Model & $214.582(11)^{*}$ & .861 & .861 & .225 & 1.724 \\
Two Factor Model & $275.726(13)^{*}$ & .821 & .848 & .235 & 1.929 \\
$\quad$ Two Factor Model & $114.023(15)^{*}$ & .929 & .922 & .169 & 1.250 \\
$\quad$ (With Method Effects) & & & & & \\
Six Item PCRM & & & & & \\
$\quad$ One Factor Model & $83.684(5)^{*}$ & .931 & .903 & .208 & 1.126 \\
$\quad$ Two Factor Model & $7.297(5)$ & .998 & .997 & .035 & 0.294 \\
\hline
\end{tabular}

Note: * Significant $p<.05$

Poor model fit suggested the need to revise the hypothesized model to better represent the pattern of participants' responses to the PCRM items. The model revision process included a close inspection of each item's content and a reevaluation of its conceptual relationship with the construct of empowerment. As a marker of empowerment, the PCRM was designed to measure primary central control, specifically, the perceived capacity for taking action (and responsibility) and in turn enacting positive life change. Inspection of item content suggested that items that asked participants about their sense of control over consequences could be better conceptualized as distinct from primary central control. On the basis of the conceptual distinction between central (items $1 \mathrm{a}$ and $1 \mathrm{~b}$ ) and consequential control ( $3 \mathrm{a}$ and $3 \mathrm{~b}$ ), items $3 \mathrm{a}$ and $3 \mathrm{~b}$ were trimmed from the model and a second set of confirmatory factor analysis were conducted on the resulting six-item measure. Trimming the model improved the fit of the one-factor model $\left(\chi^{2}(5)=\right.$ 83.684, $p<.001$; CFI $=.931$;LI $=.903$; RMSEA $=.208$, WRMR $=1.126)$, however, fit 
indices still indicated poor model fit. Trimming the model also improved the fit of the two-factor model with similar items allowed to covary $\left(\chi^{2}(5)=7.297, p=.1995\right.$; CFI $=$ $.998 ; \mathrm{TLI}=.997 ; \mathrm{RMSEA}=.035, \mathrm{WRMR}=.294)$. In this case, fit indices were consistent with good model fit, providing evidence in support of the hypothesized factor structure when items of consequential control are removed. The unstandardized and standardized parameter estimates for the championed two-factor model are presented in Figure 1 and provided evidence of construct validity. Factor loading estimates revealed that the indicators were moderately to strongly related to their hypothesized latent factors (range of $\left.R^{2} \mathrm{~s}=.38-.84\right)$.

\section{Scale Reliability Analyses}

As future studies will seek to use composite scale scores, it was necessary to estimate the scale reliability for both of the latent factors. As model-based estimation of Raykov's reliability rho was not originally developed for use with WLSMV estimator, analysis was conducted using a robust maximum likelihood estimator (Raykov, 2004). The model still provided good fit $\left(\chi^{2}(6)=3.218, p=.7811 ; \mathrm{CFI}=1.000 ; \mathrm{TLI}=1.017\right.$; RMSEA $=.001$, SRMR $=.018$ ) and no substantial changes were identified (see Figure 2 for unstandardized and standardized parameter estimates in MLR). Model-based estimates of Raykov's reliability rho for the life in general factor and life change factor were .77 and .70 , respectively, providing evidence for scale reliability. 
Figure 1: Personal Responsibility Measure: WLSMV Two-Factor Model

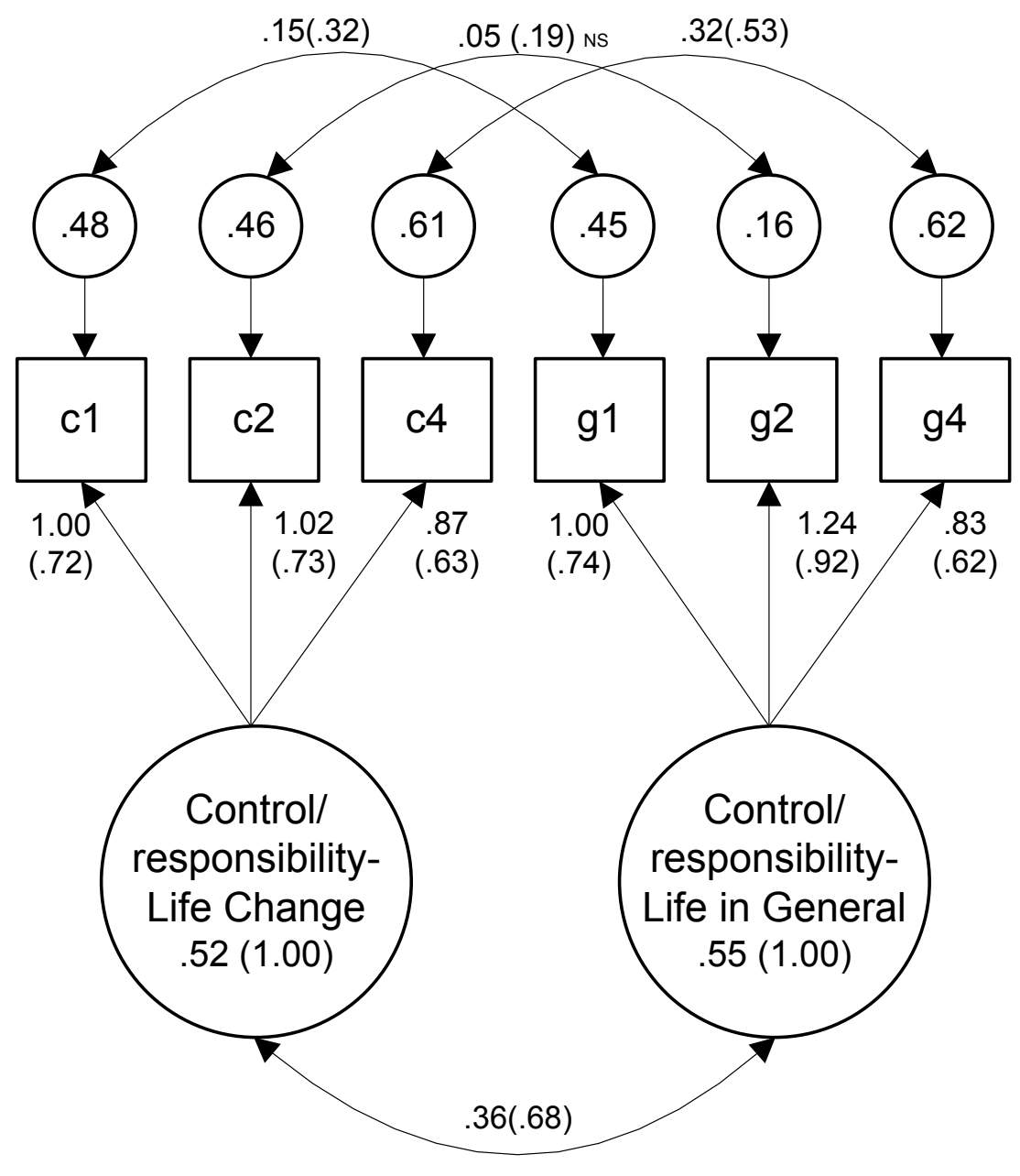

Note: Parameter and goodness-of-fit estimates were obtained using the weighted least squares mean and variance adjusted (WLSMV) estimator: $\chi^{2}(5)=7.297, p$ $=.199 ; \mathrm{CFI}=.998 ; \mathrm{TLI}=.997 ; \mathrm{RMSEA}=.035, \mathrm{WRMR}=.294$. 
Figure 2: Personal Responsibility Measure: MLR Two-Factor Model

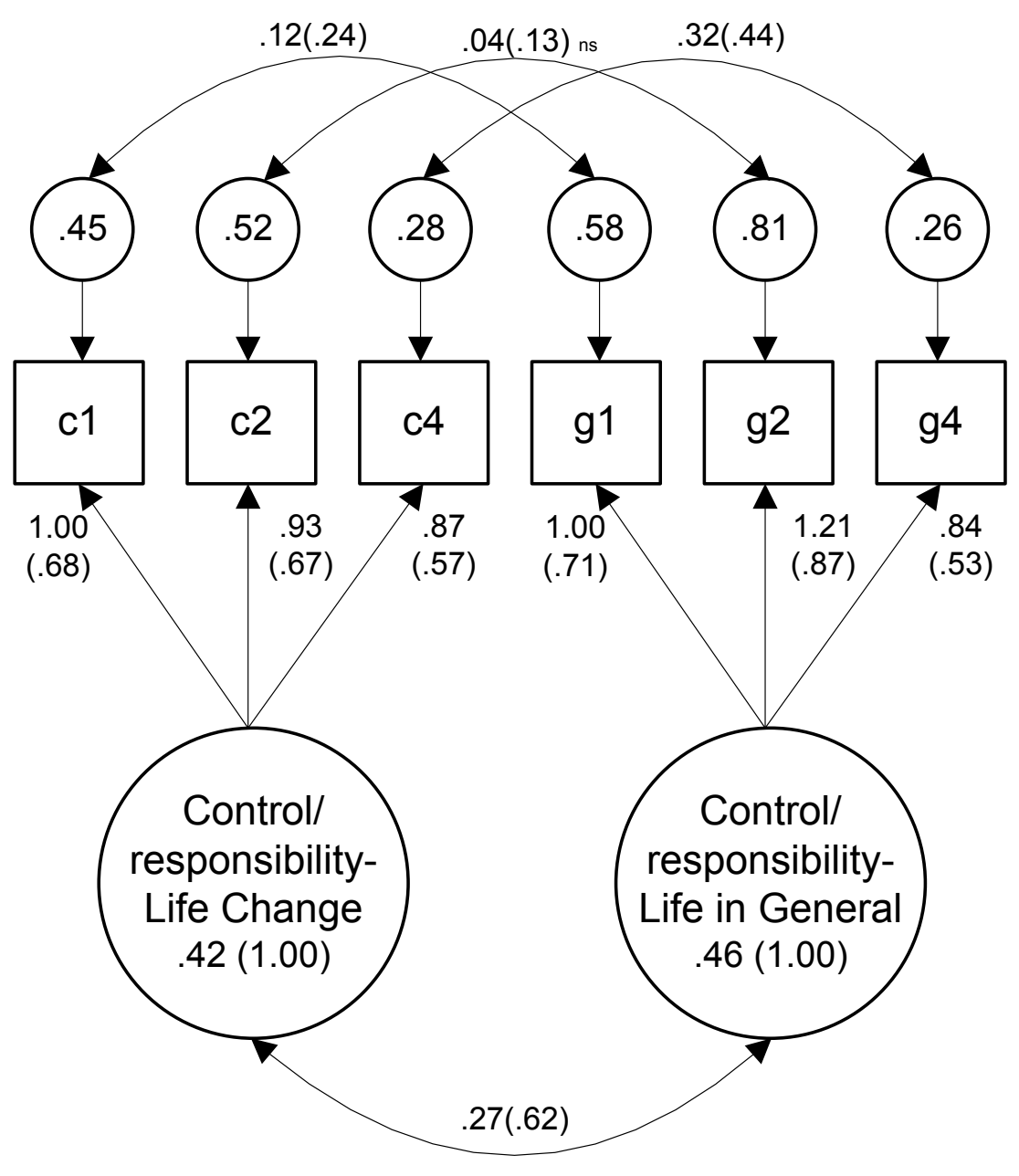

Note: Parameter and goodness-of-fit estimates were obtained using the Robust Maximum Likelihood (MLR) estimator: $\chi^{2}(5)=2.434, p=.786$; CFI $=1.000$; $\mathrm{TLI}=1.019 ; \mathrm{RMSEA}=.000, \mathrm{SRMR}=.017$.

\section{Measurement Invariance}

Next, the current study sought to evaluate whether the PCRM's properties are invariant across subgroups. Measurement invariance was evaluated in Mplus 5.0 using a multi-group solution with robust maximum likelihood estimator. There are key 
advantages of using a multi-group solution framework over other methods traditionally used to examine group differences (e.g., interaction contrasts). These advantages include the capacity to examine all aspects of measurement invariance including equal form (configural invariance), equal factor loadings (metric invariance), equal intercepts (scalar invariance), and equal indicator residuals (strict factorial invariance; Brown, 2006). This allows investigators to ensure, that across groups, the assessment measurement is able to target the same constructs (equal form), that items function similarly (equal factor loadings and intercepts), and finally, whether the unique (unaccounted) variance of items are equivalent (equal indicator error and factor variance). Measurement invariance was evaluated separately across intervention groups (Control and CLP), gender (male and females), and ethnicity (Hispanics and African Americans). Furthermore, since future studies will seek to examine for change across time, the current study also evaluated for longitudinal measurement invariance. All analysis began with the least restricted solution and progressed towards increasingly restrictive constraints using nested $\chi^{2}$ methods to evaluate significant differences across models.

Intervention Measurement Invariance. Following Brown's (2006) recommendations for multiple-group confirmatory factor analysis invariance testing, the two factor structure (CRG and CRLCG) were tested in each group (Comparison and CLP) separately. Model fit estimates for both the control $\left(n=270 ; \chi^{2}(5)=6.59, p=.252\right.$; $\mathrm{CFI}=.995 ; \mathrm{TLI}=.985 ; \mathrm{RMSEA}=.034 ; \mathrm{SRMR}=.030)$ and the intervention conditions $\left(\mathrm{n}=270 ; \chi^{2}(5)=4.35, \mathrm{p}=.500 ; \mathrm{CFI}=1.000 ; \mathrm{TLI}=1.018 ; \mathrm{RMSEA}<.001 ; \mathrm{SRMR}=.033\right)$ indicated good model fit (see Table 5). Next, equal form was evaluated by testing the same factor structure for both groups (Comparison and CLP) in a multiple-group 
analysis. Model fit estimates indicated a good fitting model $\left(\chi^{2}(14)=12.39, p=.256\right.$;

$\mathrm{CFI}=1.000 ; \mathrm{TLI}=1.008 ; \mathrm{RMSEA}<.001 ; \mathrm{SRMR}=.030)$.

Table 5: Measurement Invariance by Condition

\begin{tabular}{llllllc}
\hline & \multicolumn{3}{c}{ Model Fit } & \multicolumn{2}{c}{ Invariance Test } \\
\hline & $\chi^{2}(\mathrm{df})$ & CFI & TLI & RMSEA & SRMR & $\chi_{\text {Diff }}^{2}$ \\
\hline Single Group Solution & & & & & & \\
$\quad$ Control (n=270) & $6.59(5)$ & 0.995 & 0.985 & .034 & .030 & \\
$\quad$ CLP (n=95) & $4.35(5)$ & 1.000 & 1.018 & $<.001$ & .033 & \\
Measurement Invariance & & & & & & \\
$\quad$ Equal Form & $12.39(14)$ & 1.000 & 1.008 & $<.001$ & .030 & \\
$\quad$ Equal Factor Loading & $13.06(18)$ & 1.000 & 1.018 & $<.001$ & .034 & $0.66(4)$ \\
$\quad$ and Intercepts & & & & & & \\
$\quad$ Equal Error Variance & $25.58(24)$ & 0.990 & 0.987 & 0.032 & .081 & $12.52(6)$ \\
\hline
\end{tabular}

Note: $* p<.05 * * p<.01$

Having satisfied equal form, the analysis progressed to a more restricted solution, equal factor loadings and intercepts. Analysis of equal factor loadings is a critical test as it determines equivalence in the meaning and structure of the measure (Brown, 2006). Model fit estimates for the equal factor loading and intercept model indicated good model fit $\left(\chi^{2}(18)=13.06, p=.788 ; \mathrm{CFI}=1.000 ; \mathrm{TLI}=1.018 ; \mathrm{RMSEA}<.001 ; \mathrm{SRMR}=.034\right)$; model fit did not significantly decrease relative to the equal form solution $\left(\chi_{\text {Diff }}^{2}(4)=.66\right.$, $\mathrm{p}=.956$ ). Thus, findings indicate that for any given factor value, the observed value of each indicator will be equivalent across comparison and intervention groups.

Having met equal form, equal factor loadings, and equal intercepts, analysis progressed to examine equality of equal error variance. As seen in Table 5, the equal indicator residuals solution was found to be indicative of good fit. However, $\chi^{2}$ difference test revealed a marginally significant decrease in model fit relative to the equal factor 
loading and intercept solution $\left(\chi^{2}\right.$ Diff $\left.(6)=12.52, p=.051\right)$. Equality of error variance tends to be rare in applied research (Brown, 2006). Furthermore, equal error variance or strict factorial invariance has been regarded as an overly restrictive test and not crucial for the evaluation of measurement invariance (Byrne, 1998).

Gender Measurement Invariance. The next phase in the current study was to examine invariance across gender. Once again, prior to running a multiple-group CFA invariance model, the two factor structure was tested separately for men and women. Model fit estimates for both men $\left(n=161 ; \chi^{2}(5)=1.26, p=.939 ; C F I=1.000\right.$; TLI=1.064; $\operatorname{RMSEA}<.001 ; \operatorname{SRMR}=.017)$ and women $\left(\mathrm{n}=180 ; \chi^{2}(5)=3.08, \mathrm{p}=.688 ; \mathrm{CFI}=1.000\right.$; TLI=1.028; RMSEA<.001; SRMR=.020) indicated good model fit (see Table 6). Next, equal form was evaluated. Once again, model fit estimates indicated good fit $\left(\chi^{2}(14)=6.87, \mathrm{p}=.939 ; \mathrm{CFI}=1.000 ; \mathrm{TLI}=1.039 ; \mathrm{RMSEA}<.001 ; \mathrm{SRMR}=.025\right)$ allowing for more restrictive models of measurement invariance. Analysis of equality for both equal factor loading/intercepts and equal error variance both met criteria for good model fit and did not significantly decrease the model fit $\left(\chi^{2}\right.$ Diff $(4)=8.38, p=.078$ and $\chi^{2}$ Diff $(6)=2.91$, $\mathrm{p}=.820$ respectively). Thus, findings provided evidence for full measurement invariance across men and women.

Table 6: Measurement Invariance by Gender

\begin{tabular}{lcccccc}
\hline & \multicolumn{5}{c}{ Model Fit } & \multicolumn{2}{c}{ Invariance Test } \\
\hline & $\chi^{2}(\mathrm{df})$ & CFI & TLI & RMSEA & SRMR & $\chi^{2}$ Diff \\
\hline Single Group Solution & & & & & & \\
$\quad$ Men (n=161) & $1.26(5)$ & 1.000 & 1.064 & $<.001$ & .017 & \\
$\quad$ Women (n=180) & $3.08(5)$ & 1.000 & 1.028 & $<.001$ & .020 & \\
Measurement Invariance & & & & & & \\
$\quad$ Equal Form & $6.87(14)$ & 1.000 & 1.039 & $<.001$ & .025 & \\
$\quad$ Equal Factor Loading & $15.26(18)$ & 1.000 & 1.012 & $<.001$ & .064 & $8.38(4)$
\end{tabular}


and Intercepts

Equal Error Variance

$18.17(24) \quad 1.000 \quad 1.019<.001$

.085

2.91(6)

Note: $* p<.05 * * p<.01$

Ethnic Measurement Invariance. Concluding research aim three, invariance across ethnic groups was analyzed next. However, because of low representation of ethnic groups (i.e., White, Asian, American Indian/Alaskan Native, Other, and Bi-Ethnic groups $<15 \%)$ ), only African American and Hispanics were kept for analysis of ethnic group measurement invariance. Model fit estimates for both Hispanic $\left(n=103 ; \chi^{2}(5)=2.42\right.$, $\mathrm{p}=.789 ; \mathrm{CFI}=1.000 ; \mathrm{TLI}=1.063 ; \mathrm{RMSEA}<.001 ; \mathrm{SRMR}=.020)$ and African American $\left(\mathrm{n}=163 ; \chi^{2}(5)=4.38, \mathrm{p}=.495 ; \mathrm{CFI}=1.000 ; \mathrm{TLI}=1.010 ; \mathrm{RMSEA}<.001 ; \mathrm{SRMR}=.026\right)$ indicated good fit (see Table 7). Next, equal form was evaluated. Model fit estimates indicated good fit $\left(\chi^{2}(14)=17.07, p=.253 ; \mathrm{CFI}=.991 ; \mathrm{TLI}=.981 ; \mathrm{RMSEA}=.041\right.$; $\mathrm{SRMR}=.042$ ). Analysis of equality for both equal factor loading/intercepts produced a solution with good fit and no substantial decrease in model fit relative to the equal form solution $\left(\chi_{\text {Diff }}^{2}(4)=3.34, p=.502\right)$. Finally, the model was examined for equal error variance. As seen in Table 7, the resulting solution did not meet the criteria for either the $\chi^{2}$ Goodness of Fit $\left(\chi^{2}(24)=38.33, p=.032\right)$ or the Standardized Root Mean Square Residual (SRMR=.126) test of model fit. Furthermore, the model was found to produce a substantial decrease in model fit relative to equal factor loading and intercept models $\left(\chi_{\text {Diff }}^{2}(6)=17.92, p=.006\right)$. However, as previously mentioned, equality of error variance is not crucial for the evaluation of measurement invariance (Byrne, 1998). Thus findings provide evidence for measurement invariance across Hispanics and African Americans. 
Table 7: Measurement Invariance by Ethnicity

\begin{tabular}{ccccccc}
\hline & \multicolumn{4}{c}{ Model Fit } & \multicolumn{2}{c}{ Invariance Test } \\
\hline & $\chi^{2}(\mathrm{df})$ & CFI & TLI & RMSEA & SRMR & $\chi_{\text {Diff }}^{2}$ \\
\hline Single Group Solution & & & & & & \\
$\quad$ Hispanic (n=103) & $2.42(5)$ & 1.000 & 1.063 & $<.001$ & .020 & \\
$\quad$ Woman (n=163) & $4.38(5)$ & 1.000 & 1.010 & $<.001$ & .026 & \\
Measurement Invariance & & & & & & \\
$\quad$ Equal Form & $17.07(14)$ & 0.991 & 0.981 & .041 & .042 & \\
$\quad$ Equal Factor Loading & $20.41(18)$ & 0.993 & 0.988 & .032 & .059 & $3.34(4)$ \\
$\quad$ and Intercepts & & & & & & \\
$\quad$ Equal Error Variance & $38.33(24)^{*}$ & 0.958 & 0.948 & .067 & .126 & $17.92(6)^{* *}$ \\
\hline
\end{tabular}

Note: ${ }^{*} p<.05 * * p<.01$

Longitudinal Measurement Invariance. Because future studies will seek to examine the effect of participation of the intervention on change in control and responsibility over life in general (CRG) and life change goals (CRLCG), the fourth aim of the study was to evaluate the PCRM for longitudinal measurement invariance. As stated by Brown (2006), "in the absence of such evaluation, it cannot be determined whether temporal change observe in a construct is due to true change or to changes in the structure of measurement of the construct over time" (pp. 252). While a multi-group solution can be applied for examining longitudinal measurement invariance, the use of a single sample assessment allows the model to take into account the lagged relationship between indicators as well as the within-time covariances (Brown, 2006). Thus, the model was evaluated with latent variables CRG and CRLCG constrained to be structurally the same across Time 1 and Time 2. Furthermore, the model allowed for correlated error of repeated measures (e.g. CRG1_1 with CRG1_2). 
Table 8: Longitudinal Measurement Invariance

\begin{tabular}{lcccccc}
\hline & \multicolumn{4}{c}{ Model Fit } & Invariance Test \\
\hline & $\chi^{2}(\mathrm{df})$ & CFI & TLI & RMSEA & SRMR & $\chi^{2}$ Diff \\
\hline Equal Form & $44.59(36)$ & 0.991 & 0.984 & .024 & .044 & \\
Equal Factor Loading & $43.72(40)$ & 0.995 & 0.991 & .015 & .063 & 0.87 \\
Equal Intercepts & $46.58(44)$ & 0.996 & 0.994 & .012 & .068 & 2.84 \\
Equal Error Variance & $49.18(5)$ & 1.000 & 1.002 & $<.001$ & .078 & 2.61 \\
\hline Note: $* p<.05 * * p<.01$ & & & & & &
\end{tabular}

As seen in Table 8, the estimated solution for equal form was found to produce a good fitting model $\left(\chi^{2}(36)=44.59, \mathrm{p}=.154 ; \mathrm{CFI}=.991 ; \mathrm{TLI}=.984 ; \mathrm{RMSEA}=.024\right.$;

$\mathrm{SRMR}=.044)$. Given the evidence for equal form, the analysis proceeded to examine temporal equality across factor loadings by constraining repeated indicators (e.g., CRG1 at baseline and CRG1 at post-test) to be equal. The constrained model produced good model fit $\left(\chi^{2}(40)=43.72, \mathrm{p}=.316 ; \mathrm{CFI}=.995 ; \mathrm{TLI}=.991 ; \mathrm{RMSEA}=.015 ; \mathrm{SRMR}=.063\right)$. Taking the absolute value of the $\chi^{2}$ Diff, no significant differences were found between equal form and equal indicator solutions $\left(\chi_{\text {Diff }}^{2}=0.87, \mathrm{p}=.928\right)$. Next, with the exception of CRG01 and CRLCG01 which are fixed at 1 to set the scale for the latent variable, the indicator intercepts were constrained to be equal across time. The additional constraint did not lead to a substantial decrease in model fit relative to the equal indicator model $\left(\chi_{\text {Diff }}^{2}=2.84, \mathrm{p}=.584\right)$. Thus, findings suggest that mean change over time can be attributed to change in the true score of the construct and not the result of temporally unstable relationships or inequality in indicator's location parameters over time (Brown, 2006). The final temporal constraint that was placed was equality of error variance. There were no substantial decreases found in model fit relative to the equal intercept model $\left(\chi_{\text {Diff }}^{2}=2.61, \mathrm{p}=.856\right)$. 


\section{DISCUSSION}

The CLP intervention, through proactive transformative activities, seeks to empower at-risk youth attending alternative high schools. Empowerment in turn, is hypothesized to establish contexts for transformative change in the students' sense of self

and identity as agents capable of self and societal change (Montgomery, et al., 2008). The Personal Control and Responsibility Measure (PCRM) was developed in order to assess individuals' perceived control and responsibility over self-selected life change goals and life in general (Rice, Berman, Ferrer, Kurtines, 1996). Preliminary evaluation found significant intervention effects on control and responsibility over life change goals and life in general; however, these evaluations were undertaken without in-depth evaluation and validation of the measure (Meca, unpublished honors thesis). The current study sought to rectify this by examining the dimensionality of the PCRM and verifying the hypothesized underlying factors as well as evaluating psychometric consistency of the PCRM across groups (condition, ethnicity, and gender).

\section{Dimensional Analysis}

Examination of the theoretical model for the 8-Item Personal Control and Responsibility Measure indicated inadequate fit for both a one-factor and a two-factor model. In light of the inadequate fit, the model revision process included a close inspection of each item's content and a reevaluation of its conceptual relationship with the construct of empowerment. Inspection of item content suggested that items that asked participants about their sense of control over consequences could be better conceptualized as distinct from primary central control and responsibility over actions 
and consequences. That is, perceived control over actions (items 1a and 1b) and responsibility over these actions (items $2 \mathrm{a}$ and $2 \mathrm{~b}$ ) and their consequences (items $3 \mathrm{a}$ and 3b) are likely to be qualitatively different from perceived control over the consequences of these actions (items $3 a$ and $3 b$ ).

One example of this conceptual difference can be seen in an individual that reported "improving family issues" as his life change goal. When prompted on his level of control and responsibility over his actions ("spending more time with my family"), he reported to have "total control" (a five on the likert scale). However, when asked how much control he has over the consequences of these actions, he reported to have only "some control" (a three on the likert scale). The participant may have potentially felt that his actions play only a partial role in the outcome with aspects beyond his control (the reaction of their parents to spending time) playing an equal if not greater part. Research on perceived control has distinguished between central and consequence-related control, with empirical evidence for this conceptual distinction (Thompson, Nanni, \& Levine, 1994). It is for this reason that items $3 \mathrm{a}$ and $3 \mathrm{~b}$ were dropped. Analyses found the trimmed two-factor model to be consistent with good model fit.

Psychometric analysis of reliability for CRLCG and CRG using Raykov's Rho revealed acceptable reliabilities of .70 and .76 . Despite this, and in light of the correlated method effect for similarly worded items, a cautionary note is given to researchers seeking to create and implement observed summated composite scores. The use of summated composite scores of CRLCG and CRG respectively would be contaminated with construct-irrelevant variance. Specifically, the if composite scores of CRLCG and 
CRG were correlated with each other, observed correlations would be biased upward, because of significant positive correlations between similarly worded items over and above the variance accounted for by the measured constructs.

\section{Measurement Invariance}

Evaluation of whether a scale's measurement properties are invariant across subgroups is an important aspect of scale development (Brown, 2006). As the current study serves to build the foundation for future evaluations of the Changing Lives Program in empowering adolescents, measurement invariance across condition was of primary important. Furthermore, previous evaluations of the CLP have found intervention effects moderated by gender and ethnicity across a wide variety of outcomes (Albrecht, 2008; Eichas, 2010). For that reason, measurement invariance across gender and ethnicity was of equal importance.

Results provided evidence for invariance in form, factor loadings, and intercepts across condition, gender, and ethnicity. Furthermore, with the exception of ethnicity, the analysis found equal error variance across groups, a stringent test of measurement invariance (Brown, 2006). While findings demonstrated measurement invariance, this does not imply that groups scored equally. Instead, findings suggest that the PCRM is able to equally asses the level of individuals control and responsibility over life change goals and life in generals for males and females, Hispanics and African Americans, and participants in the CLP that were referred to counseling and those in the comparison control. It is only once measurement equivalence has been established that future studies 
can seek to examine group differences (differences in the mean and variance of latent variables) in the targeted constructs (CRLCG and CRG).

\section{Limitations and Directions for Future Research}

While the results of the current study provide evidence for the validity and reliability of the revised Personal Control and Responsibility Measure, the current study, conducted with the use of the CLP's archival data, had several limitations. First, the reliance on archival data limits the flexibility of further examining the underlying construct in question. Expanding the PCRM beyond the primary eight items to include multiple indicators of potentially distinct dimensions (responsibility over actions and consequences) was not possible. Additionally, while the current study found invariance across Hispanic and African American subgroups, examination of invariance across other ethnic groups was not possible to examine because of lack of representation in the sample. Thus, whether or not the PCRM is invariant across other ethnicities is still an unanswered question. Moreover, while the CLP may have theoretically related constructs (e.g., Psychological Well-Being and Personal Expressiveness, etc.) the CLP dataset lacks similar measures of perceived control (i.e., Measures of locus of control, self-efficacy, helplessness) to explore convergent and divergent validity. Finally, although the primary goal of the current study was to validate the PCRM for further evaluation of the Changing Lives Program, the level of generalizability of the current findings cannot be assessed given the specific sample (i.e., alternative high school students in a large, urban school district). The extent to which the PCRM serves as a valid and reliable tool for measuring individuals' level of control and responsibility for adolescents in mainstream 
institutions (as opposed to alternative high schools) must be further addressed in future studies.

Despite the aforementioned limitations, the current study serves as a stepping stone for future evaluations of the Changing Lives Program by operationalizing the primary targeted mechanism of intervention change, empowerment. As an indicator of the empowerment process and a targeted PYD outcome, future studies should examine whether the intervention is able to promote increases in control and responsibility over life change goals (CRLCG) and life in general (CRG). Furthermore, consistent with the CLP's Participatory Transformative approach, future studies should examine whether increases in CRLCG and CRG are associated with and/or mediate intervention increases in positive identity processes (e.g., identity commitment). Such findings would be consistent with Schwartz, Côté, and Arnett (2005) who found agentic orientations, with indicators including perceived control, associated with higher likelihood of achieved identity status.

It is important to note that while other measures could be applied for evaluating individuals' perceived primary control, the PCRM is able to provide a general control and responsibility measure, as well as a contextually embedded one. Specifically, as part of the Participatory Transformative Approach, individuals choose aspects of their own lives they wish to change and are taken through the process of weighing methods for achieving these goals. Thus, control and responsibility over life change goals is individually salient. Consistent with empowerment theory, which emphasizes context specific measures and a PYD approach that acknowledges development across the life course as emerging from 
person $\leftrightarrow$ environment interactions. Consequentially, the PCRM, specifically the CRLCG subscale, only provides a quantitative measure and does not account for variation in intra-individual self-selected life change goals. Using a Relational Data Analysis Approach (Kurtines et al., 2008) for coding open-ended questions, future studies should incorporate individual's life change goals for qualitatively distinct categories that may moderate intervention effects or relationships between CRLCG and other variables.

By providing evidence for the validity and reliability of the Personal Control and Responsibility Measure as well demonstrating psychometric consistency across condition, ethnicity (African American and Hispanics), gender, and across time (Time 1 and Time 2), the current study establishes a starting point for further evaluations of empowerment in the Changing Lives Program. Whether or not the CLP is able to empower adolescents to become the "experts" in their own lives is now an empirical question that may be now addressed. 


\section{References}

Arnett, J.J (1999). Adolescent storm and stress, reconsidered. American Psychologist, 54(5), 317-326.

Arnett, J.J, Kurtines, W.M., Montgomery, M.J. (Eds.) (2008). Promoting positive youth development [Special issue]. Journal of Adolescent Research, 23.

Balcazar, F. E., Seekins, T., Fawcett, S. B., \& Hopkins, B.L., (1990). Empowering people with physical disabilities through advocacy skills training. American Journal of Community Psychology, 18, 281-296.

Bandura, A. (1997). Self-efficacy: The exercise of control. New York, Freeman.

Benson, P. L. (1997). All kids are our kids: What communities must do to raise caring and responsible children and adolescents. San Francisco, CA: Jossey-Bass.

Benson, P. L., Scales, P. C., Hamilton, S. F., Sesma, A. Jr. (2006). Positive youth development: theory, research, and application. In W. W. Damon \& R. M. Lerner (Eds.), Handbook of child psychology, Volume 1, Theoretical models of human development. New York: John Wiley.

Berman, S. L., Kurtines, W.M., Silverman, W.K., \& Serafini, L.T. (1996). The impact of exposure to crime and violence on urban youth. American Journal of Orthopsychiatry, 66(3), 329-336

Briones, E. (1997). Social and cultural influences in the formation of identity: Acrossnational/cultural study. Unpublished doctoral dissertation, Florida International University, Miami.

Brown, T. A. (2006). Confirmatory factor analysis for applied research. New York: The Guildford Press.

Catalano, R. F., Kosterman, R., Hawkins, J. D., Newcomb, M. D., \& Abbott, R. D. (1996). Modeling the etiology of adolescent substance use: A test of the social development model. Journal of Drug Issues, 26(2), 429-455.

Catalano, R. F., Berglund, M. L., Ryan, J. A. M., Lonczak, H. S., \& Hawkins, J. D. (2004). Positive youth development in the United States: Research findings on evaluations of positive youth development programs. The Annals of the American Academy of Political and Social Science, 591, 98-124.

Chavis, D.M., \& Wandersman, A. (1990). Sense of community in the urban environment: A catalyst for participation and community development. American Journal of Community Psychology, 18, 55-81. 
Cornell Empowerment Group (1989). Empowerment and family support. Networking Bulletin, 1, 1-23.

Csikszentmihalyi, M. (1998). The development of the person: An experiential perspective on the ontogenesis of psychological complexity. In Damon, W. \& Lerner, R.M. (Eds.), Handbook of child psychology, Vol 1: Theoretical models of human development. New York, NY: Wiley.

Damon, W. (2004). What is positive youth development? Annals of the American Academy of Political \& Social Science. Special Positive Development: Realizing the Potential of Youth, 591, 13-24.

Eichas, K., Albrecht, R. E., Garcia, A. J., Ritchie, R. A., Varela, A., Garcia, A., Rinaldi, R., Montgomery, M. J., Silverman, W. K., Jaccard, J., \& Kurtines, W. M. (2010). Mediators of positive youth development intervention change: Promoting change in positive and problem outcomes. Child and Youth Care Forum.

Elder, G. H. (1998). The life course and human development. In R. M. Lerner (Ed.), Handbook of child psychology, Vol 1: Theoretical models of human development. New York, NY: Wiley.

Erikson, E. H. (1968). Identity: Youth and crisis. New York: Norton.

Freire, P. (1973). Education for critical consciousness. New York: Seaburry.

Furstenberg, F. F., Jr., \& Hughes, M. E. (1995). Social capital and successful development among at-risk youth. Journal of Marriage and the Family, 57, 580592.

Kieffer, C. H. (1984). Citizen empowerment: A developmental perspective. Prevention in Human services, 6, 1-174.

Kurtines, W. M., Azmitia, M., \& Alvarez, M. (1992). Science, values, and rationality: Philosophy of science from a co-constructivist perspective. In W. M. Kurtines, M. Azmitia, \& J. L. Gewirtz (Eds.), The role of values in psychology and human development (pp. 3-29). New York: Wiley.

Kurtines, W. M., Berman, S. L., Ittel, A., \& Williamson, S. (1995). Moral development: A co-constructivist perspective. In W. M. Kurtines \& J. L. Gewirtz (Eds.), Moral development: An introduction (pp. 337-376). New York: Wiley.

Kurtines, W. M., Ferrer-Wreder, L., Berman, S. L., Lorente, C. C., Briones, E., Montgomery, M. J., Albrecht, R., Garcia, A. J., \& Arrufat, O. (2008a). Promoting positive youth development: The Miami Youth Development Project (YDP). Journal of Adolescent Research, 23(3), 256-267. 
Kurtines, W. M., Ferrer-Wreder, L., Berman, S. L., Lorente, C. C., Silverman, W. K., \& Montgomery, M. J. (2008b). Promoting positive youth development: New directions in developmental theory, methods, and research. Journal of Adolescent Research, 23(3), 233-244.

Kurtines, W. M., Montgomery, M. J., Eichas, K, Ritchie, R., Garcia, A., Albrecht, R., Berman, S., Ferrer-Wreder, L., \& Lorente, C. C. (2008c). Promoting positive development in troubled youth: A Developmental Intervention Science outreach research approach. Identity: An International Journal of Theory and Research, 8, $125-138$.

Lerner, R. M. (2005, September). Promoting positive youth development: Theoretical and empirical bases. White paper: Workshop on the Science of Adolescent Health \& Development, NRC/Institute of Medicine. Washington, DC: National Academies of Science.

Lerner, R. M., Fisher, C. B., \& Weinberg, R. A. (2000). Toward a science for and of the people: Promoting civil society through the application of developmental science. Child Development, 71(1), 11-20.

Marsh, H. W. (1992). Extracurricular activities: Beneficial extension of the traditional curriculum or subversion of academic goals. Journal of Educational Psychology, $84,553-562$.

Meca, A. (2010). Positive youth development: Promoting a sense of control and responsibility over life challenges. Unpublished Honor's Thesis. Florida International University, Miami.

Mechanic, D. (1991, February). Adolescents at risk: New directions. Paper presented at the annual Conference on Health Policy, Cornell University Medical College.

Montgomery, M. J., Kurtines, W. M., Ferrer-Wreder, L., Berman, S. L., Lorente, C. C., Briones, E., Silverman, W., Ritchie, R., \& Eichas, K. (2008). A Developmental Intervention Science (DIS) outreach research approach to promoting youth development: Theoretical, methodological, and meta-theoretical challenges. Journal of Adolescent Research, 23(3), 268-290.

Muthen, L. K. \& Muthen, B. O. (1998-2007). Mplus User's Guide (5 ${ }^{\text {th }}$ ed). Los Angeles, CA: Muthen \& Muthen.

Ramirez-Valles, J., Zimmerman, M. A., \& Juarez, L. (2000). Gender differences of neighborhood and social control processes: A study of the timing of first intercourse among urban African-American youth. Youth \& Society, 33, 418-441. 
Rappaport, J. (1984). In praise of paradox: A social policy of empowerment over prevention. American Journal of Community Psychology, 9, 1-25.

Raykov, T. (2004). Estimation of Maximal Reliability: A Note on a Covariance Structure Modelling Approach. British Journal of Mathematical and Statistical Psychology, 57, 21-27.

Rice, J., Berman, S., Ferrer, L., \& Kurtines,W. (1996, April). The development and validation of a self-report measure of personal responsibility. Paper presented at the Society for Research on Adolescence, Boston, MA.

Rounsaville, B. J., Carroll, K. M., \& Onken, L.S.. (2001). A stage model of behavioral therapies research: Getting started and moving on from stage I. Clinical Psychology: Science and Practice, 48, 133-142.

Schulz, A.J., Israel, B.A., Zimmerman, M.A., \& Checkoway, B.N. (1995). Empowerment as a multi-level construct: Perceived control at the individual, organizational, and community levels. Health Education Research Theory \& Practice, 10, 309-327.

Schwartz, S. J., Cote, J. E., \& Arnett, J. J. (2006). Identity and agency in emerging adulthood: Two developmental routes in the individualization process. Youth and Society, 37(2), 201-229.

Seligman, M. \& Csikszentmihalyi, M. (2000). Positive psychology. American Psychologist, 55(1), 5-14.

Stone, R. A., \& Levine, A. G. (1985). Reactions to collective stress: Correlates of active citizen participation. Prevention in Human Services, 4, 153-177.

Sue, S., \& Zane, N. (1980). Learned helplessness theory and community psychology. In M. S. Gibbs, J. R. Lachenmeyer, \& J. Sigal (Eds.). Community Psychology: Theoretical and empirical approaches (pp. 121-143), New York: Gardner.

Thompson, S. C., Nanni, C., \& Levine, A. (1994). Primary versus secondary and disease versus consequence-related control in HIV-positive men. Journal of Personality and Social Psychology, 64, 540-547.

Waterman, A. S. (1992). Identity as an aspect of optimal psychological functioning. In G. R. Adams, T. P. Gullotta, \& R. Montemayor (Eds.), Adolescent identity formation: Advances in adolescent development (pp. 50-72). Newbury Park, CA: Sage.

Wilson, D. K., Rodrigue, J. R., \& Taylor, W. C. (1997). Health-promoting and healthcompromising behaviors among minority adolescents. Washington, DC: American Psychological Association. 
Zimmerman, M.A. (1995). Psychological Empowerment: Issues and illustrations. American Journal of Community Psychology, 23(5), 581-599.

Zimmerman, M. A. (2000). Empowerment theory: Psychological, organizational and community levels of analysis. In J. Rappaport \& E. Seidman (Eds.), Handbook of community psychology (chap. 2, pp. 43-63). New York: Plenum.

Zimmerman, M.A., Stewart, S.E., Morrel-Samuels, S., Franzen, S., \& Reischl, T. M. (2011). Youth Empowerment Solutions for Peaceful Communities: Combining Theory and Practice in a Community-Level Violence Prevention Curriculum. Health Promotion Practice 12, 425-439.

Zimmerman, M. A., \& Maton, K. I. (1992). Lifestyle and substance use among urban black male adolescents: A cluster analytic approach. American Journal of Community Psychology, 20, 121-138.

Zimmerman, M.A., Israel, B.A., Schulz, A., \& Checkoway, B. (1992). Further explorations in empowerment theory: An empirical analysis of pathological empowerment. American Journal of Community Psychology, 20, 707-727.

Zimmerman, M.A., \& Rappaport, J. (1988). Citizen participation, perceived control, and psychological empowerment. American Journal of Community Psychology, 16, 727-750. 